\title{
STORYTELLING - THE PAST AND THE PRESENT
}

\author{
Sue Walton
}

\begin{abstract}
The care people receive when their illness moves along the continuum from curable to one when death is imminent needs to be personalised and holistic. Palliative care requires health professionals who have a person-centered approach, and a willingness to listen and get alongside people during vulnerable times. As a registered nurse, working in an inpatient unit of a hospice, I explore here a palliative care critical incident that incorporates the story of a memorable patient, 'Bob'.

Stroebe and Schut's (1999) dual process model of coping with bereavement provides a psychological interpretation of grief, oscillating between feeling the pain and getting on with life. Rather than linear, progressional stages or phases of grief the dual process model incorporates loss and restoration orientations. The bereaved person moves back and forth between emotion-focused grief work and task-focused learning of new roles and skills.

In this paper I link Bob's palliative care experience to the Stroebe and Schut (1999) model to show how the impact of loss and bereavement can be immense and seemingly overwhelming; however, adjustment and coping can be facilitated through patient centered palliative care.
\end{abstract}

\section{INTRODUCTION}

Creating and sharing meaning through storytelling is a constructive process, with context and meaning intertwined (Rolls \& Payne, 2008). Storytelling facilitates 'coming to terms' with difficult experiences. For patients new understandings are gained as the past is reframed, making sense of the present and providing direction for the future. Co-construction and developing alternative versions of a story is an important part of healing and clinical care. For health professionals, stories shed light on practice and experience surrounding illness that might not otherwise be recognised. Learning and understanding about others is gained, as insight is shared when something has not been per- 
sonally experienced (Garro \& Mattingly, 200o). At times illness reality may seem ordinary to health professionals; however, the illness experience may be extraordinary to the sufferer. Health professionals need to listen to patients' stories to not only learn about physiological reality and effective intervention, but also human suffering. Focusing on the person, what is significant in their lives, and how things matter to them, is essential for therapeutic relationships (Canning, Rosenberg, \& Yates, 2007).

There are often many sides to a story. For health professionals storytelling and reflection on practice are valuable ways of exploring, making sense of, and learning through experiences with patients, and have the potential to enhance effectiveness and caring. Meanings and issues are embedded within a story and can reveal what is going on professionally and personally. As a story is told, certain aspects of practice and of the situation are highlighted, such as care goals, challenges, changes, constraints, and the characters of those involved. Sharing our stories with others enables us to take on new perspectives. Learning through reflection and experience encourages health professionals to be more responsible and accountable for their practice (McDrury \& Alterio, 2002).

Our thinking becomes visible and real to others, and in a safe setting it has the potential for enhancing working relationships. Storytelling along with reflection on practice can enable opportunities for sense to be made and meaning gained from challenging situations (Schon, 1983). This is especially the case in palliative care, which provides unique challenges to health professionals. In such cases, death will not be avoided through treatment, but is the inevitable end point of care.

Palliative care nursing promotes a person-centered approach incorporating respect, trust, genuineness, empathy, recognition of individuality, and a willingness to get alongside people during vulnerable times (Green, 2006). To enhance coping and healing, addressing emotional, spiritual, psychosocial as well as physical needs of patients and their families is paramount. The ongoing challenge for health professionals is to demystify death and grief, and by doing so reduce vulnerability and anxiety.

In this article, I explore storytelling and reflection on practice using an example from my own experience in palliative nursing. In the following section I introduce Bob, an elderly patient who I cared for when he was admitted for respite care. The setting for Bob's story is the inpatient unit of a hospice, and the story is told from my registered nurse perspective. Names have been 
changed to protect anonymity. Stroebe and Schut (1999) promote two concepts, loss orientation and restoration orientation, which oscillate as a person adapts and adjusts their life to bereavement and loss. This bereavement model will also be discussed in relation to Bob.

What really matters is emphasised in the following prose based on Dame Cicely Saunders philosophy for hospice care (du Boulay, 1984).

\author{
You matter because \\ you are you. \\ You matter to the \\ last moment of your life. \\ And we will do all we can \\ not only to help you \\ die peacefully, \\ but also to live until you die.
}

BOB'S STORY: THE WAR WAS OVER BUT THE BATTLE CONTINUED

I had the privilege of getting to know Bob, an 86 year old man whom I cared for while working afternoon shifts as a registered nurse in the hospice inpatient unit. Bob's kindness, acceptance of his situation, appreciative nature and quiet ways impressed me. He was married to Martha and they had had '62 good years so far'. She visited and they sat close, talked freely and touched each other tenderly. He was alert and caring and still in his role as husband and father; after all, he was only visiting the hospice. His home and the greater community was where he felt he belonged and wanted to return.

Bob had served in World War II with the army, returning home battle weary to work and family. The NZ Railways had provided employment all his working life, involving shift work and a variety of jobs over the years. He retired at 65 years in good health and enjoyed home maintenance activities with Martha, fishing with mates, gardening, socialising, and driving 'here and there. He had no health concerns until he was 74 when diabetes was diagnosed, which he self-managed. Six years ago was 'a very bad year' when a prostatectomy was performed, followed by a surgical removal of an ascending colon tumour a few months later. Despite these health challenges and adjustments Bob regained his energy and control over his life. Bob continued to be the home and financial manager for his family. Being in control was important to him and Martha had not challenged this over the years. 
Bob's health situation did, however, deteriorate with evidence of metastatic spread to his liver. On admission to the hospice for respite care, his energy was easily expended, imposing limitations and the need for assistance with his personal care and mobility. He was alert and interested in life, enjoyed his meals and the company of other patients and hospice staff. It was just after I had started the afternoon shift that Bob and I first connected. After reassuring him that I had the time for a chat his eyes lit up, he straightened himself in his chair and we 'chewed the fat'. He was reminiscing and sharing about his children, work and interests. Holidaying together at their coastal crib was a highlight, which Bob described as 'a rough sort of a place, (two rooms only), a lot of fun, swimming, shooting, fishing, getting away together.' He also said that he had 'both good and sad memories'.

Later on Bob asked me to give him a hand to get to bed. He said he had had a good day but was feeling more tired than usual so he accepted my gentle assistance out of the chair and up onto his walking frame. He smiled and thanked me. He enjoyed walking, little and often being the approach, even though he was getting weaker. It was private in the bathroom and Bob looked at me and said, 'I'm sorry about last night'. This prompted me to rethink the handover from the morning team - yes, he had had a 'really bad night'. As a team we had discussed at length the possible causes for Bob's night distress, but our brainstorming had ended inconclusively.

As we sat together I asked him what had happened. He described how he had woken up frightened, thinking he was trapped in the trenches of World War II. 'All I could hear was ringing in my ears, and I felt overwhelmed by memories of my dead and injured comrades.' His head was hanging down and his shoulders were drooped. His story quietly tumbled forth, vividly even though it was so long ago.

Over the years I have kept these thoughts and feelings to myself. I feel close to Martha but haven't wanted to burden her and get her down. I've been a very private man up until now and wouldn't have talked to anybody about these things. Keeping busy has helped in the past.

I said very little and only asked a few open-ended questions. He reached out for my hand, patting it gently as he thanked me. With tears in my eyes I thanked him for being willing to risk his life by fighting for our country. As a younger New Zealander I had indeed reaped huge benefits from such bravery. 
I asked Bob what I could do to make the night ahead different for him. He knew and quickly stated, 'I need my over-bed light on, a torch and the curtains open a little so I can see the trees outside'. Is that all, I thought to myself, and promptly reassured Bob that I would do these things for him, which I did. It was great to hear at handover the next day that Bob had slept peacefully all night. Hearing this made me feel good, reinforcing the importance of connecting, active listening, and staying in the moment, as well as the value of reflecting on and learning from my own feelings.

Reminiscing and thinking about his own imminent death had, indeed, impacted Bob, and he needed to make sense of his past. Bob's heartrending wartime past reinforced for me how ordinary men were expected to do the extraordinary. Personally I had been emotionally ignited because of the impact of my own father's war realities. Today we call the result of such experiences 'posttraumatic stress' and appropriate support is available. Bob had managed to live on, but he was still battling. Professionally the time with Bob encompassed therapeutic interpersonal moments and care within the nursing context of 'privileged intimacy' (de Hennezel, 1998). As a nurse it is a privilege to be with someone at times of vulnerability and be able to provide care when independence has decreased. The paradox of professional distance and intimate contact within nurse-patient relationships can be a challenge, necessitating balance, self-awareness and ongoing self-care.

Palliative care requires health professionals who will integrate a person-centered approach into their therapeutic relationships and care. Person-centeredness incorporates respect, trust, genuineness, empathy and recognition of individuality to facilitate positive change and address emotional, psychological and physical needs related to end of life care (Green, 2006). Caring is paramount. Caring cannot be subdivided or allocated, because it is emotional and personal, encompassing mutuality and reciprocity to provide support and reduce vulnerability. Psychological and social aspects of caring include understanding, warmth, mutual trust and belief (Janssen \& MacLeod, 2010). As time is purposefully spent and experiences shared, fresh insights can be gained into the difficulties of a situation, giving rise to opportunities that enhance coping. Importantly, it is not the activity itself that decides whether it is perceived as 'caring, but the manner in which it is performed and the appropriateness of the action to the situation. Facilitating someone's coping and helping them make sense of their loss and bereavement can be based on different models and processes (Small, 2001). 
Since the 1960's loss and bereavement theory has been greatly developed and revised, focusing mainly on human reactions to loss rather than effective ways of coping with bereavement. Identified were stages of grief (Bowlby, 1973; Kubler Ross, 1969; Parkes, 1972) and coping with loss based on tasks (Worden, 1991). Other theorists have described stressor(s) and psycho-social reactions associated with bereavement (Parkes, 1993), identified predictors of outcomes (Sanders, 1989) and explained aspects of meaning reconstruction (Neimeyer, 1998; Walter, 1996).

Stroebe and Schut's (1999) dual process model of adaptive coping draws on previous bereavement and stress theories and models. The dual process model challenges the linear, progressional, stages/phases of previous bereavement models, which have often been used prescriptively and emphasised the end point rather than the process. Grief work is necessary if adjustment and coping with change is to be achieved. Stroebe and Schut (1999) propose that confronting loss is essential for adaptive grieving, however not relentlessly, but in 'doses'. The dual process model provides an interpretation of grief that oscillates between feeling the pain and getting on with life. The bereaved person can move back and forth between emotion-focused grief work and learning new roles and skills. The model has two types of stressors: loss orientation and restoration orientation, which incorporate facing up to the loss and also to making major adjustments in one's life. It is restoration that is about not returning to the previous way of living, but to a new way of living with the loss. An essential, distinguishing feature of this model is the oscillation that occurs between the two orientations as the person alternatively confronts and then avoids the different aspects of grieving (see Figure 1).

Stroebe and Schut (1999) claim this model can also be applied to complicated grief, which might best describe Bob's grief. He had suppressed his grief and trauma over a long time, which was not unusual for a man of his age. Dealing with his grief in this way has resulted in repressed behaviour as he buried his grief along with his dead war comrades. However, as he reminisced, unresolved issues and grief were revisited differently, and he was able to finally resolve his past experiences (Coleman, 1989).

Taking into consideration the dual process model means that there is a conscious endeavour to engage with Bob's worldview and bereavement construction, not just one's own. At a personal level, my perspectives of grief and bereavement are influenced by the idiom 'a trouble shared is a trouble halved'. 


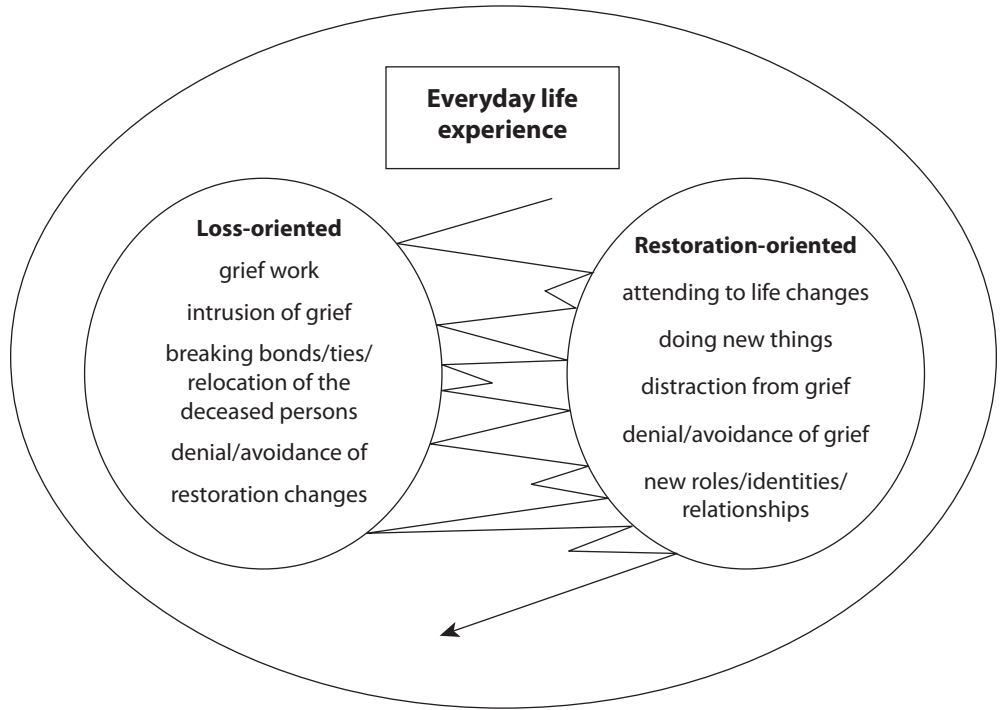

Figure 1: A Dual Process Model of Coping with Bereavement

Grief incorporates the need for expression and confrontation of loss through the sharing of grief feelings and experiences (Arnold \& Boggs, 2003). It is important as a health professional, however, to acknowledge clearly my own grief assumptions and accept that there are many ways to grieve. Facilitating bereavement coping and enhancing healing may also be achieved through times of non-confrontation, avoidance behaviour and strategies (Stroebe \& Schut, 1999). Applying the dual process model to Bob's grief means facilitating expression of his grief and coping, as well as enabling him to keep busy or be occupied, so that he could have 'time out'. Bob said he felt stronger, making it possible for him to make sense of what had happened in the past. He wanted to be more in control of his life, thinking and talking about his more recent cancer-related losses, and the anticipated changes he was yet to face. He knew he was gradually losing strength and independence, so wanted to plan his future care and funeral.

Bob's deteriorating health meant he was having to cope with 'imposed' respite care. 'Imposed' refers to the situation being externally determined, as he gave his wife a break and well-earned rest. Bob felt he had little or no control over his situation yet he reluctantly complied, and this stressor potentially exceeded his resources and increased his vulnerability. However, according to Stroebe and Schut (1999) this situation could be described as 'oscillation', and Bob 
chose to use this experience as an opportunity to confront and explore his war-time grief. As Bob reminisced, he talked of being profoundly affected by the deaths and disfigurement of friends and comrades and had not known how to deal with this. He emphasised that the men who returned from war were grateful to still be alive and just wanted to forget the harsh war times and get on with their new lives.

Social and cultural contexts impact on grieving and need consideration because societies have sets of norms or cultural scripts for how to express grief. These norms influence who, when, where, how, how long, and who should be grieved for (Walter, 1999). In Bob's case societal and familial expectations impacted his reality following his return from the war to the extent that he kept his grief to himself, hidden from others. Bob reiterated that his deep sense of loss and feelings associated with war events were minimised and masked, as the celebration of returning 'home' and being alive dominated their existence. There was no follow-up or ongoing contact from Army personnel on his return, and the common approach of this time was to suppress the grief (Walter, 1999). In effect society 'silenced' the grief of the young men who returned and they were expected to just get 'over the war' by rebuilding their lives (Dent \& Stewart, 2004). Bob's own psychosocial reality at this time reinforced 'moving on and forgetting about things. War-related bereavement has been, and still is, acknowledged through annual public ANZAC (Australian \& New Zealand Armoured Corps) rituals and ceremonies. However, reintegration into social and family life was emphasised after returning from the war. Bob attempted to manage his loss and grieving by keeping his feelings to himself but his life had been changed forever.

The complexities often associated with palliative care and bereavement support require ongoing assessment, planning, and evaluation. Stroebe and Schut's (1999) dual process model accommodates changes in a person's coping, but effective teamwork based on communication, collaboration and a commitment to patient-focused outcomes is necessary. My encounter with Bob was made possible because my colleague and I were able to adjust to changing patient needs and support each other as spontaneous things happened. We were able to 'go with the flow', making time for care that included conversations, massage, and listening to families and each other as part of our shift. The time available to spend with patients is often constrained by workloads, which can be a frustration. Not giving the 'busy' message, but instead being relaxed and focused, can indeed be a challenge. Bob appreciated my 'giving time' and 'being available. Gathering meaningful information to facilitate grieving must be ongoing, and one must not assume that they understand a person's coping and where 
they may be at with their grief (Heaney, 2002). Actual or anticipatory grief responses to bereavement can be large or small, and this is for the grieving person to define. Wanting to determine someone's coping and adaptation according to bereavement and grief models that focus on 'moving on' rather than the oscillatory nature of the dual process model can be an ongoing temptation.

Bob's story reinforces the notion that very often deep, pertinent information can remain undisclosed and that the person will choose to whom, when, where, and if they will disclose. The dual model highlights how perspectives shift and moods change, so sensitivity is paramount. Effective interpersonal communication between a patient and health professional is vital in palliative care when the aim is to enhance situational control, alleviate anxieties and promote quality of life (Wallace, 2001). Quality of life issues need addressing, so listening to the person and their family is very important. As experiences are shared, coping strategies, which may, or may not have worked in the past for the person can be explored. The impact of loss and bereavement on people's lives can be immense and seemingly overwhelming. When new understandings are explored and incorporated into a person's whole life that is, behaviourally, physically, socially, intellectually and spiritually they are enabled to adapt to loss.

Using the oscillation aspect of Stroebe and Schut's (1999) dual process model, one could have mistakenly assumed Bob and Martha were in a 'timeout' position. After all, Bob was at the hospice for respite care because they were emotionally and spiritually very tired. However, quite the opposite transpired. Even though facing the future seemed difficult and fraught with anxiety, choosing to confront his grief was helpful. As Bob took time to reflect and reminisce, he was able to face up to not only his past bereavements, but also his own death. Psychosocial, emotional and spiritual issues in palliative care need to be incorporated as part of caring for the whole person (Green, 2006). Integrating grief into one's life can be an ongoing, changing experience incorporating 'a periodic, deliberate walk backwards while keeping a sure foot in living forward' (Moules, Simonson, Prins, Angus \& Bell, 2004:99). As Bob dealt with his grief, spiritual strength and coping was drawn from others and from his beliefs, enabling him to make sense of his life and face the future as he prepared for the end of his life.

CONCLUSION

As health professionals, it is indeed a privilege to facilitate moments of connection and accompany people as they grieve and make sense of loss and 
bereavement experiences. One key difference with Stroebe and Schut's (1999) dual process model is the 'oscillating' between feeling the pain and getting on with life. Healing occurs as people combine times of confronting their grief with 'time-out' from their grief experience. There is no prescription for grieving; the oscillation between loss and restoration orientations, rather than linear stages/phases of grief, allows for ongoing adjustments to life, as difference is faced and energy reinvested in new situations and relationships.

The capacity to be with someone expressing strong emotions is challenging, so a person-centered approach is necessary. Critical reflection on practice is necessary. Critical reflection needs to include thinking about one's own beliefs, to enhance being available for the grief experiences of others. The ongoing challenge for health professionals is to demystify death and grief, to reduce vulnerability and anxiety and to enhance coping and healing.

Storytelling and reflection on practice uncover one's values, theories, attitudes and assumptions used in practice. In relation to bereavement and grief, reflection on practice can empower oneself and others, as stories unfold and shape professional and personal development. The losses and subsequent grief of one person cannot be compared with the losses and grief of another person, even when the losses appear to be of a similar nature. To address emotional, psychosocial, spiritual and physical needs, health professionals must have a person-centered approach, respecting the person's individuality and their grief experience.

It is a privilege to develop therapeutic relationships and for all involved to gain insight. When we share a story we share a part of ourselves. Storytelling has the capacity to connect and liberate, enabling us as health professionals to walk alongside others.

\section{REFERENCES}

Arnold, E. and K. Boggs, 2003 Interpersonal Relationships (4th edition), Missouri, USA: Elsevier Science.

Bowlby, J. 1973 Loss: Sadness and Depression, New York: Basic Books.

Canning, D., J. Rosenberg and P. Yates, 2007 Therapeutic Relationships in Specialist Palliative Care Practice, International Journal of Palliative Nursing, 13(5):222-29. 
Coleman, P. 1989 Ageing and Reminiscence Processes, UK: John Wiley \& Sons.

de Hennezel, M. 1998 Intimate Distance, European Journal of Palliative Care, 5(2):56-9.

Dent, A. and A. Stewart, 2004 Sudden Death in Childhood: Support for the Bereaved Family, Edinburgh: Butterworth Heinemann.

du Boulay, S. 1984 Cicely Saunders The Founder of the Modern Hospice Movement, London: Hodder and Stoughton.

Garro, L and C. Mattingly, 2000 Narrative as Construct and Construction, in C. Mattingly, and L. Garro (eds) Narrative and the Cultural Construction of Illness and Healing, California: University of California Press: 1-49.

Green, A. 2006 A Person-Centered Approach to Palliative Care Nursing, Journal of Hospice and Palliative Nursing, 294-301.

Heaney, P. 2002 Coming to Grief, Dunedin, New Zealand: Longacre Press.

Janssen, A. and R. MacLeod, 2010 What Does Care Mean? Perceptions of People Approaching the End of Life, Palliative and Supportive Care, 8:433-40.

Kubler Ross, E. 1969 On Death and Dying, New York: Macmillan

McDrury, J. and M. Alterio, 2002 Learning Through Storytelling: Using Reflection and Experience in Higher Education Contexts, Palmerston North, New Zealand: Dunmore Press.

Moules, N., K. Simonson, M. Prins, P. Angus, and J. Bell, 2004 Making Room for Grief: Walking Backwards and Living Forward, Nursing Inquiry, 11(2): 99107.

Neimeyer, R. 1998 The Lessons of Loss: A Guide to Coping, New York: McGraw Hill.

Parkes, C.M. 1972 Bereavement: Studies of Grief in Adult Life, London: Tavistock.

Parkes, C.M. 1993 Bereavement as a Psychosocial Transition: Processes of Adaptation to Change. In M. Stroebe, W. Stroebe, \& R.O. Hansson (Eds.), Handbook of Bereavement: Theory, Research and Intervention, New York: Cambridge University Press: 91-101. 
Rolls, E. and S. Payne, 2008 What is the Value of Narrative Research as a Form of Enquiry in Palliative Care Nursing?, International Journal of Palliative Nursing, 14(12): 576-7.

Sanders, C. M. 1989 Grief: The Mourning After, New York: Wiley.

Schon, D. 1983 The Reflective Practitioner: How Professionals Think in Action, New York: Basic Books.

Small, N. 2001 Theories of Grief: A Critical Review, in J. Hockey, J. Katz, and N Small (eds) Grief, Mourning and Death Ritual, Buckingham: Open University Press: $19-48$.

Stroebe, M. and H. Schut, 1999 The Dual Process of Coping with Bereavement: Rationale and Description, Death Studies, 23:197-224.

Wallace, P. 2001 Improving Palliative Care Through Effective Communication, International Journal of Palliative Care, 7(2):86-90.

Walter, T. 1996 A New Model of Grief: Bereavement and Biography, Mortality, 1:7-25.

Walter, T. 1999 On Bereavement: The Culture of Grief, Buckingham, UK: Open University Press.

Worden, J. W. 1991 Grief Counseling and Grief Therapy: A Handbook for the Mental Health Practitioner, New York: Springer. 